\title{
Complementarity in Time between Hydro, Wind and Solar Energy Resources in the State of Rio Grande do Sul, in Southern Brazil
}

\author{
Marcos Bagatini, Mariana G. Benevit, Alexandre Beluco, Alfonso Risso \\ Instituto de Pesquisas Hidráulicas (IPH), Universidade Federal do Rio Grande do Sul (UFRGS), Porto Alegre, Brazil \\ Email: albeluco@iph.ufrgs.br
}

How to cite this paper: Bagatini, M., Benevit, M.G., Beluco, A. and Risso, A. (2017) Complementarity in Time between Hydro, Wind and Solar Energy Resources in the State of Rio Grande do Sul, in Southern Brazil. Energy and Power Engineering, 9, 515-526.

https://doi.org/10.4236/epe.2017.99036

Received: January 20, 2017

Accepted: August 21, 2017

Published: August 24, 2017

Copyright (@) 2017 by authors and Scientific Research Publishing Inc. This work is licensed under the Creative Commons Attribution International License (CC BY 4.0).

http://creativecommons.org/licenses/by/4.0/ (c) (i) Open Access

\begin{abstract}
This work studies the complementarity between hydro, wind and solar photovoltaic energy in the Brazilian state of Rio Grande do Sul. Brazil is a country highly dependent on hydro energy; however, the existent plants are not being able to cover the energy demand in recent years. In this context, the state of Rio Grande do Sul becomes important because of its potential for wind and solar photovoltaic energy, having complementarity between water, wind and solar photovoltaic schemes when hydroelectric reservoirs are at their lowest levels. This study aims to survey the complementarity of various parts of Rio Grande do Sul by proposing mathematical dimensionless ratios, focusing on intra-annual period to carry out a mapping of the entire state. It also analyses the ability to provide power supply throughout the year, through the stabilization of the energy supply, which depends on an adequate scale for photovoltaic, wind power and hydroelectric harnessing. According to the results obtained, the regions with the best complementarity indexes for deployment of a hybrid system in relation to water and wind power were the Metropolitan Region of Porto Alegre and the Southeast region, and the same regions also presented the best results for the complementarity between hydro and solar photovoltaic. Regarding wind and solar photovoltaic energy, the state's northeast region presented the best results. Finally, the Northeast region of the state also presented the best results for the three energies together.
\end{abstract}

\section{Keywords}

Energetic Complementarity, Complementarity Maps, Hydropower, Wind Energy, Solar PV, Southern Brazil

\section{Introduction}

The maintenance of an adequate supply of energy in a region depends on how 
its energy matrix is composed, taking into account the existence and availability of a set of energy sources [1]. The performance of each individual source (hydro, wind and solar) over a period of time varies due to its seasonality, which may require the activation or deactivation of thermal generators (from fossil fuels or biofuels). For a given energy demand, to verify how the available natural sources complement one another is a point of interest, since it is possible to evaluate the need for thermal complementation of the system, an option that is always more expensive and more polluting.

The structure of power generation of the Brazilian electrical system is essentially characterized by the presence of large generation centers, in which hydroelectric units are predominant [2]. The hydro power corresponds to $74.8 \%$ of the country's electric energy matrix, according to data from the National Electric System Operator (ONS) [3].

The seasonal variation of energy supply in systems linked to this generation structure presents a great challenge to its operators, often requiring the support from thermoelectric plants. This occurs because hydrological regimes have a random character with markedly seasonal fluctuations, possibly complementary along the Brazilian territory.

Thus, hydropower has proved to be efficient but not sufficient to cover Brazilian energy demand in recent years, being necessary the search for new energy alternatives. The installation of renewable complementary sources could represent a solution to this problem, reducing the influence of the seasonal fluctuations of the hydro energy supply.

The southern state of Brazil, Rio Grande do Sul [4], has high potential for complementarity with respect to solar and wind energy, in relation to the already widely used hydroelectricity. This state also presents stations with concomitant data of water flow, wind velocity, and solar radiation, which enables a specific analysis for the use of hybrid systems.

Thus, Rio Grande do Sul was selected for this study that analyzes the complementarity between hydropower, wind and solar photovoltaic energy sources to carry out a mapping that identifies viable sites for use of the hybrid system. Next, it aims to map the different regions through contour lines to verify the gradual differences and the locations with high potential for complementarity between hydro, wind and photovoltaic solar resources.

The information generated in this study aims to update the survey maps already made, in order to facilitate the analysis of the implantation of small and large systems, bringing economic benefits. This paper also intends to contribute to the discussion about energetic complementarity and the expression of complementarity through maps.

\section{Complementarity between Different Energy Resources}

The expression complementarity between energy sources refers to the capacity of energyresources to present complementary energy availabilities. Comple- 
mentarity may occur in time, space, or both. And it can also occur considering the same source or between different sources. Complementarity in space may exist when the energy availabilities of two or more sources complement each other over a region. Complementarity in time can exist when the energy availabilities of two or more sources have periods that complement each other over time in the same region.

The energy availabilities of two sources at a given location may be considered complementary in time if equal periods and their respective minimum (or maximum) values are distant from each other from a range corresponding to the half of that period. In addition, they must still present equal average values and equal relations between the respective maximum and minimum values [5] [6].

The work of Beluco [7] described a case of complementarity with two sinusoidal curves. These two curves present periods equal to 1 year, mean values equal to 1 , minimum values equal to 0.8 and maximum values equal to 1.2 . The minimum value of the first curve is 0.75 year and the minimum value of the second curve is 0.25 year. The complementarity between the two curves can be characterized as perfect, since the minimum values are delayed from each other an interval equal to 0.5 year (as well as the maximum value), the difference between the maximum and minimum values is equal 0.4 in both cases, and mean values are equal.

Hybrid systems of electric power generation are formed by two or more sources of energy. In most cases, they are modeled using renewable energy sources such as wind, photovoltaic, biomass and hydroelectric dams associated with the use of diesel generators, coupled to load generators, power converters, energy storage (batteries), among other accessories of control and supervision.

Generally, a hybrid system relies on the use of a diesel generator set to ensure regularity and stability in the electric power supply [7]. However, the search for complementary sources can diminish the need of diesel generators, which could imply in less costs.

The renewable energy sources most commonly used in this type of system are solar and wind power [8]. The use of only solar energy or wind energy would present a temporal irregularity and an amplitude that would require the sizing of its components with high initial costs. A viable alternative is the use of photovoltaic and wind turbines unified in a single system, allowing the complementarity [9]. This complementarity could be obtained from the difference between the availability periods of the solar and wind energy sources, in order to satisfy the demand, obtaining in this way an increase of reliability and economy in the system as a whole.

A good sizing of the hybrid wind-photovoltaic system, in stand-alone operation for supplying electric power in isolated locations, can provide a reliable supply of electricity, reducing the need for supplementary fuel for diesel generators [10].

The integrations of wind and solar photovoltaic resources are made by the 
electricity generated by them, and can be stored in electrochemical batteries in isolated systems. This energy can be used directly in the DC form, or with the aid of a power conditioning system, in the AC form. Thus, the complementarity of this type of arrangement may be seasonal, since it would occur whenever, at certain periods, there were excellent solar radiation conditions and low wind speed intensity, or vice versa [11].

Knowledge of the availability of solar and wind energy would help in the identification of potential geographic locations for the use of a hybrid photovoltaicwind system. The use of these sources could also be associated with hydro energy, since the consolidation of an integrated electrical system, operating with hydro energy together, directs the national energy management and optimization of the use of reservoirs, providing seasonal stability of energy supply [12]. A complementarity between energy sources can then benefit the design and operation of this type of system.

The next section identifies how the wind and solar photovoltaic energies can act as complementary energy resourceswith hydro energy.

\section{Materials and Methods}

This section deals with data processing, discusses the calculation of complementarity indexes for two and three renewable energy resources, and details the preparation of energetic complementarity maps.

\subsection{Data Processing}

The analyses made in this work were based on public data collection of wind and wind flow. The hydrological flow data were acquired from the National Water Agency's (ANA) website [13], where they were obtained from historical series. The wind data was acquired on the INMET website [14].

The research involved flow data from 14 fluviometric stations in the state of Rio Grande do Sul, which are located in the municipalities of Bagé, Bento Gonçalves, Bom Jesus, Caxias do Sul, Cruz Alta, Encruzilhada do Sul, Iraí, Lagoa Vermelha, Pelotas, Porto Alegre, Rio Grande, Santa Maria, São Luiz Gonzaga and Uruguaiana, obtaining daily series for all municipalities.

The solar radiation data were obtained through the HOMER software [15] [16] [17]. Entering the latitude and longitude of the wind and flow stations in the program resulted in a table and a daily radiation chart of the 12 months of the year.

Wind speed and flow data were obtained in hourly time series, being afterwards converted to a monthly average of the year. The data of solar radiation were already obtained on monthly average, which facilitated the normalization of data for both sources of energy.

The standardization procedure is fundamental for analysis of complementarity of the energy sources with different units. In this work, monthly averages for the twelve months of the year, for the same year from both sources, were rea- 
lized, with the normalization calculation performed according to Equation (1).

$$
\text { In }=\frac{\left(X-X_{\text {min }}\right)}{\left(X_{\text {max }}-X_{\text {min }}\right)}
$$

In this Equation (1), In is the normalized index for each of the twelve months, $\mathrm{X}$ is average of the month in question, $\mathrm{X}_{\min }$ is minimum monthly average value and $\mathrm{X}_{\max }$ is the maximum monthly average value.

With the standardized data for both sources during the twelve months of the year it is possible to carry out an adequate graphical analysis.

\subsection{Complementarity Index for Two Energy Resources}

The index of complementarity in time, called as index of total complementarity $\mathrm{I}$, is an index elaborated to express the degree of complementarity between the availability of two sources of energy. $\mathrm{I}_{\mathrm{t}}$ is defined according to Equation (2) and includes the time lag evaluation (time complementarity index), the relationship between the means and between the amplitudes.

$$
\mathrm{I}=\mathrm{I}_{\mathrm{t}} \mathrm{I}_{\mathrm{e}} \mathrm{I}_{\mathrm{a}}
$$

For this equation, $I_{t}$ is the index of complementarity in time, $I_{e}$ is the index of complementarity between the mean values of availability, and $I_{a}$ is the index of complementarity between the amplitudes of variation of energy availability.

In this work, only the index of complementarity in time $\mathrm{I}_{\mathrm{t}}$ will be considered, so the index of total complementarity I depends only on this index.

The time complementarity index, $I_{t}$, is defined according to Equation (3) and evaluates the time interval between the minimum values of the availabilities of the two energy sources. If this range is half the period, the index will result in a unit. If it matches zero, that is, if the minimum values coincide in time, the index will be null. The intermediate values have a linear relationship between them.

$$
I_{t}=\frac{|d h-d e|}{\sqrt{|D h-d h||D e-d e|}}
$$

For this equation, $\mathrm{Dh}$ is the day corresponding to the maximum value of water availability, dh is day corresponding to the minimum value of water availability, De is the day corresponding to the maximum value of wind availability, and de is the day corresponding to the minimum value of wind availability.

This Equation (3) can receive as input the three sources of energy used in this work, hydropower, wind and solar photovoltaic, to be analyzed in pairs.

\subsection{Mapping Complementarity in the State of Rio Grande do Sul}

The mapping of region complementarity was performed using ArcGIS software through data interpolation in the ArcToolbox menu. The data was imported from an Excel table using the Add xy date icon and later interpolated. After the interpolation, a reclassification in the table from 0 to 1 was performed with intervals of 0.1 and then the contour lines were obtained, using the Arctoolbox 
tool again. The contour lines were cut at the border of Rio Grande do Sul to circumscribe the region of interest and minimize the extrapolation. The study region is filled by an image in different shades of colors, according to the scales presented. The result contains level lines for I values in ten ranges of 0.1 from 0 to 1 .

\section{Results and Discussion}

Using the data obtained, four maps were created for the complementary analysis of hydric and wind energy, hydroelectric and photovoltaic solar energy, wind and solar photovoltaic energy, and, finally, a map with hydropower, wind and solar photovoltaic energy. These maps were created using the partial index of time to facilitate the analysis.

The highest complementarity index I (1.0) occurred in the cities of Porto Alegre and Rio Grande between hydropower and solar photovoltaic energy, while the localities of Bento Gonçalves and Lagoa Vermelha had the same index between wind and solar photovoltaic. With respect to the complementarity between hydro and wind energy, the cities of Porto Alegre and Rio Grande presented index I (0.83). In relation to the complementarity between the three energies, the city of Lagoa Vermelha had the highest index I (0.905).

According to the map of temporal complementarity for hydro and wind energy (Figure 1), it is possible to observe that $50 \%$ of the region had a complementarity index I greater than 0.5 , which corresponds to a balance between the maximum and minimum values of complementarity. Porto Alegre and Rio Grande had the highest indexes I (0.83).

The regions with the highest indexes were the Southeast region, the Metropolitan region of Porto Alegre, the Central region and a part of the Northwest region of the state with I indexes higher than 0.5 , indicating the potential for a hybrid system.

The rest of the Southwest region, and part of the Northwest and Northeast regions had low rates, probably insufficient to use a hybrid system. In regions where the complementarity index has low values, it would be more appropriate to use only water energy, rather than a hybrid water-wind system.

According to the map of temporal complementarity between hydropower and photovoltaic solar energy (Figure 2), it was observed that about $65 \%$ of the region had complementarity indexes I greater than 0.5 and about $33 \%$ presented index above 0.8 , which corresponds to large amplitudes of variation with high indexes in their majority. Again, the cities of Porto Alegre and Rio Grande presented the highest indexes I with a maximum index equal to 1.0 for both.

The regions with the highest indexes were the Southeast, Metropolitan Region of Porto Alegre, Northeast, Center, and a part of the Southwest with indexes I above 0.5 , allowing potential sites for the hybrid system. Low values were presented in the Southwest region, Northwest region and a part of the Northeast region, probably places with small potential for a hybrid system. 


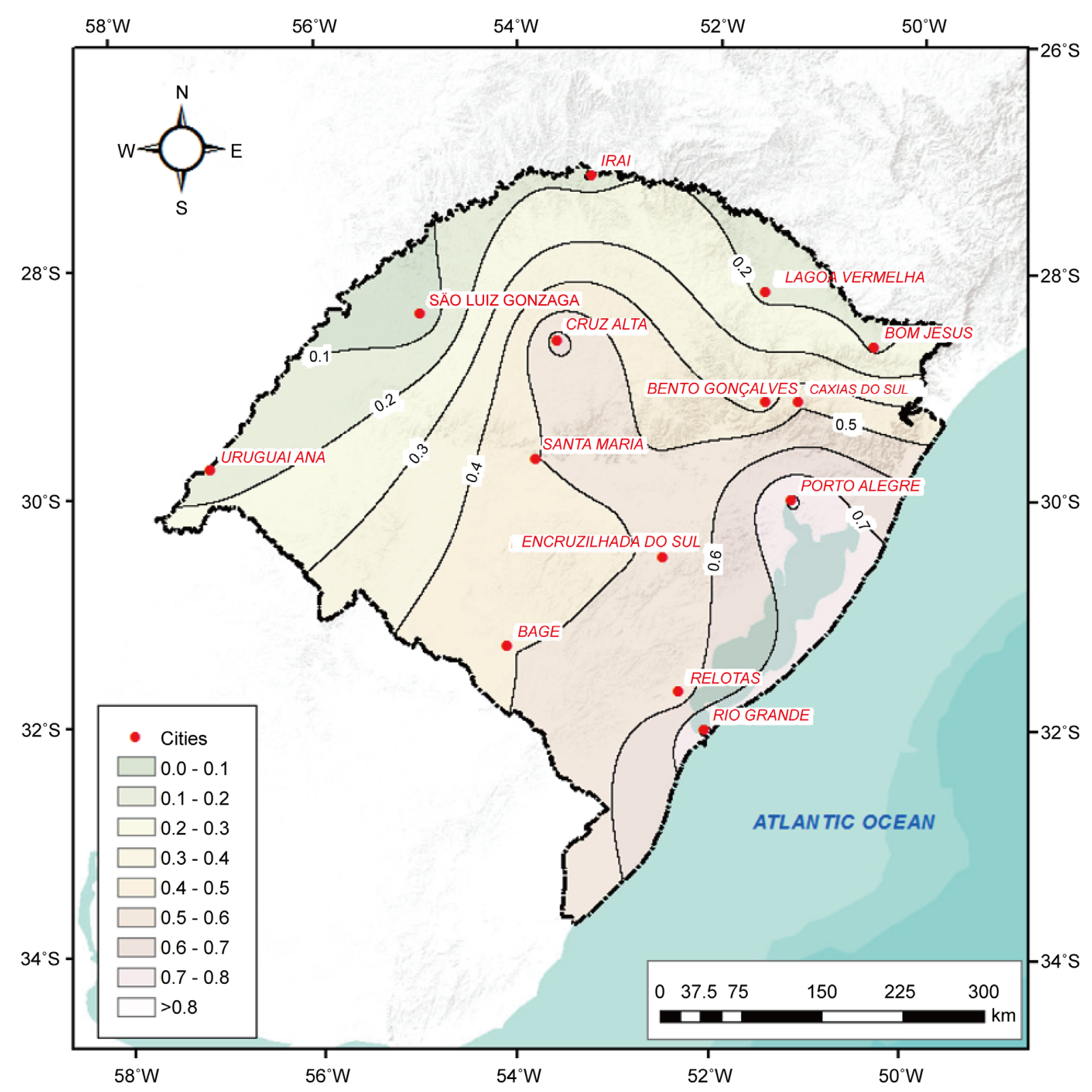

Figure 1. Map of temporal complementarity for hydro and wind energy.

Comparing the results obtained in this work with the map of Beluco [4], which also evaluates the complementarity of hydric and solar energy, it is possible to perceive some differences in the maps. For him, the highest indexes are found in the central region of the state, a strip of the Northwest region and a Southwest region with I $(0,8)$ and a point in the Center region with index I $(1,0)$. This difference is due to the data source used, since Beluco used precipitation data for the rainfall data, while the present work uses fluviometric flow data.

In regions where the complementarity index is lower, it would be more appropriate to use only hydropower than a solar-photovoltaic hybrid system. But the use of complementarity as a tool for energy resource management goes further, and it should also indicate how to prioritize enterprises formed by plants 


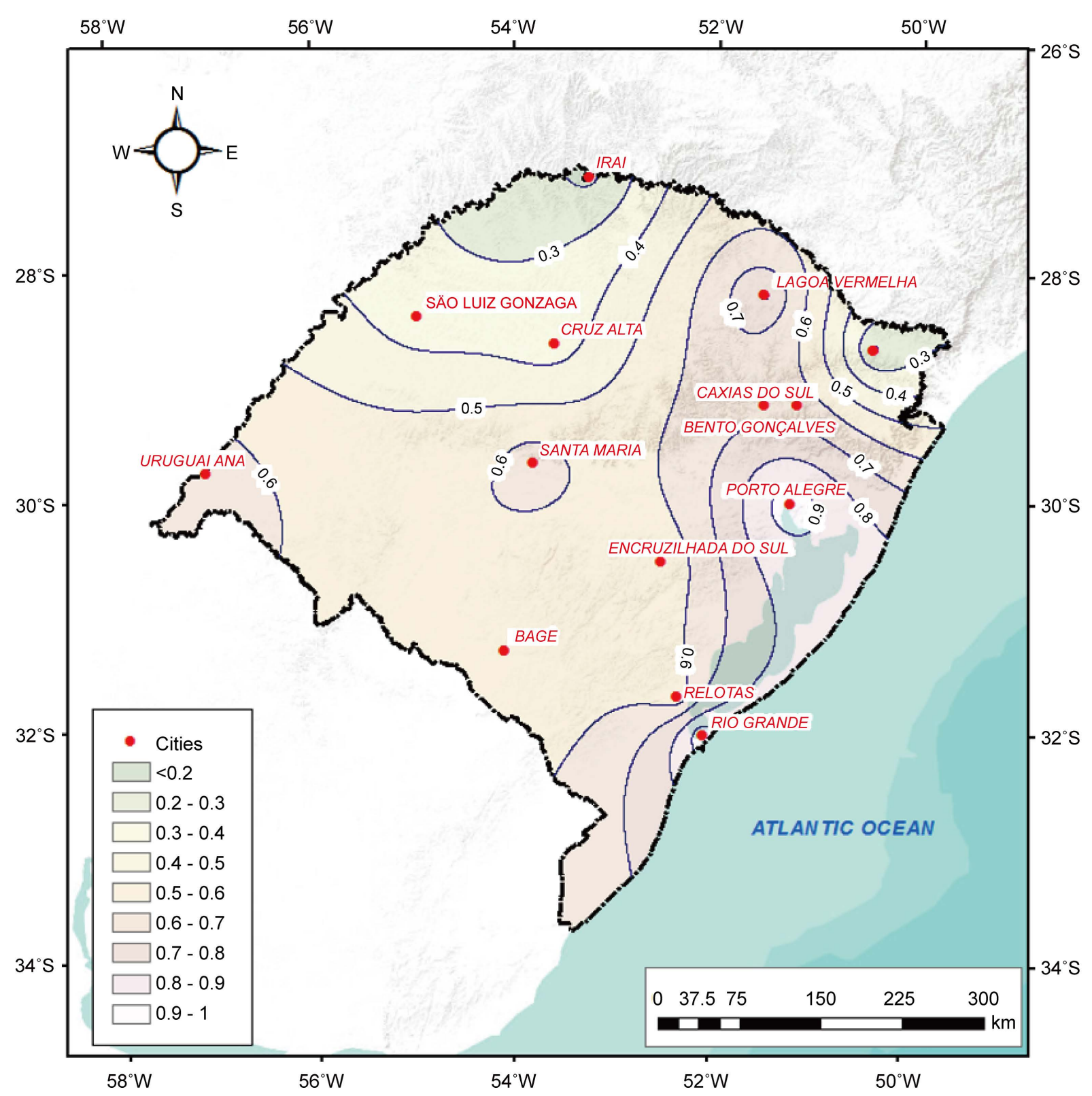

Figure 2. Map of temporal complementarity between hydropower and photovoltaic solar energy.

based on only one resource and systems based on two or more energy resources.

From the map in Figure 3, we observed that $21 \%$ of the region had a complementarity index I above 0.5 due to the large amplitude of the maximum and minimum values. Most of them resulted in low values of complementarity. The cities of Bento Gonçalves and Lagoa Vermelha had a maximum complementarity index of I equal to 1.0. The regions with the highest indexes were Northeastern region of the state and Southwest region, with I indexes higher than 0.5. The Central, Northwest and Southeast regions presented low indexes, and the hybrid system is not recommended.

The maps of Pianezzola [8], cannot be compared with this map, because in his thesis the maps were obtained with indexes of complementarity of amplitude, 


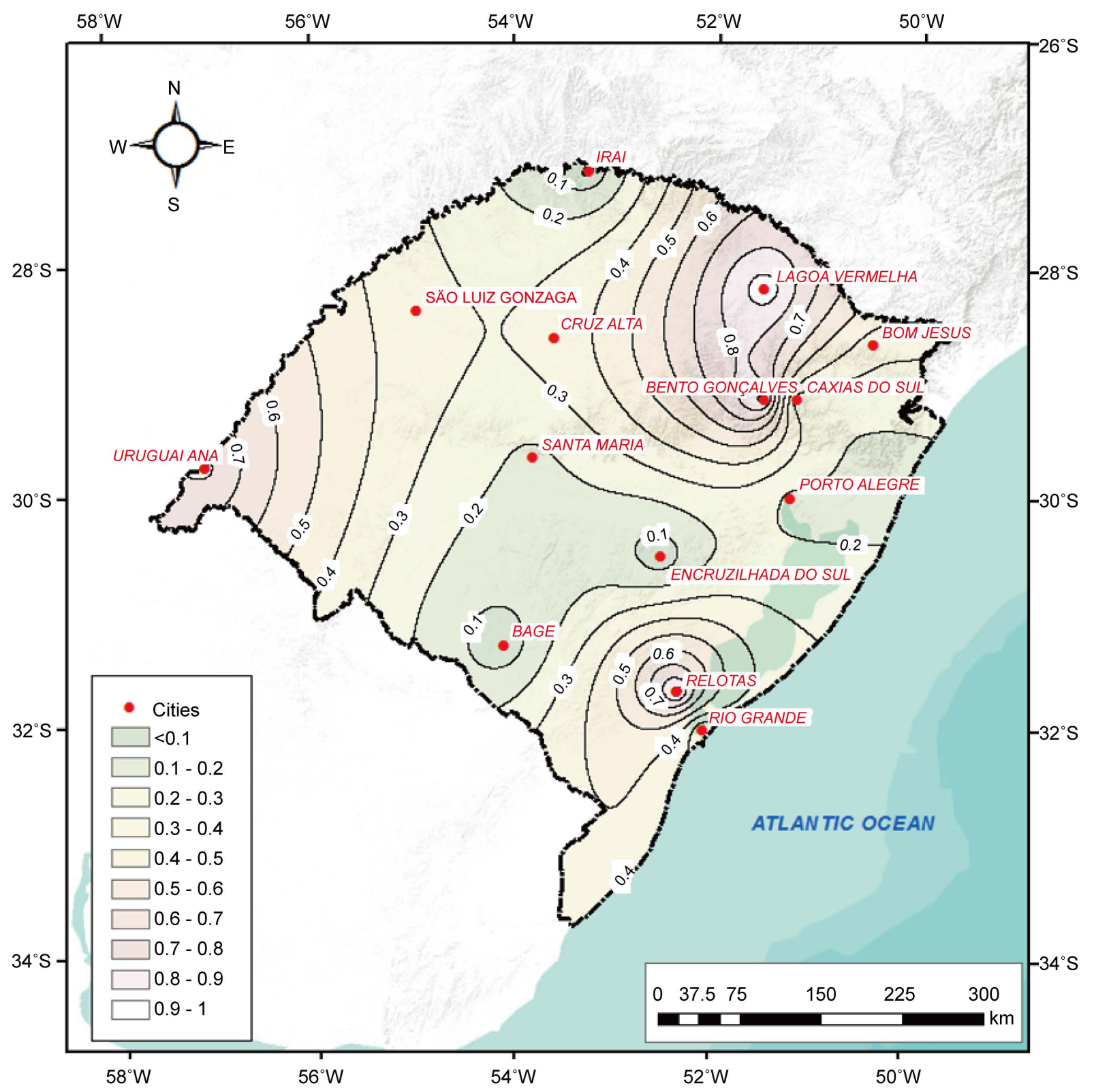

Figure 3. Map of temporal complementarity for wind and solar photovoltaic energies.

index of complementarity of time and energy, and index of total complementarity, different from the map created for this work, which uses only the complementarity index over time.

For the regions where the complementarity index is lower, it would be more appropriate to use only wind energy than a hybrid wind-solar photovoltaic system.

Observing the map of temporal complementarity between the hydro, wind and solar photovoltaic energies [1], we observed that about $65 \%$ of the regions presented complementarity indexes I above 0.8 . The city of Lagoa Vermelha obtained the highest index I, equal to 0.905 .

The regions with the highest indexes were the Northeast region, followed by 
the Metropolitan region of Porto Alegre and Central region, decreasing towards the Southeast, Southwest and Northwest regions, all with I indexes above 0.7 and with high potential for complementarity.

In comparison with the map of Borba and Brito [1], very similar indexes of complementarity I were obtained, with higher indexes located in the Northwest region of the state of Rio Grande do Sul, decreasing in the direction of the Southwest region. The values of Borba and Brito were slightly higher, varying in $90 \%$ in the range of 0.9 to 1.0 .

In comparison with the complementarity map between hydro and wind power, which presented higher I indexes in the Southeast region, the complementarity map between the three energy sources presented higher indexes in the Northeast region. In comparison with the complementarity map between hydropower and photovoltaic solar energy, which had higher I indexes in the Southeast region, the complementarity map between the three energies presented higher indexes in the Northeast region. Finally, the final map generated showed higher indexes in the Northeast region, as well as the complementarity map between wind and photovoltaic solar energy, which were previously created.

\section{Conclusions}

This work verified the complementarity in time between hydro, wind and solar photovoltaic energy in the state of Rio Grande do Sul, proving that wind and solar photovoltaic energies have potential to complement the hydroelectric generation in the state, thus contributing to the national electricity system. This contribution is associated to the availability conditions in temporal terms of energy, generating a balance in the electric energy matrix, enabling a better optimization of the reservoirs and allowing them to be used during periods of drought.

Thus, this work contributes with a study for the complementarity between hydro, wind and solar photovoltaic energies in the state of Rio Grande do Sul with dimensionless indexes for the creation of maps of complementarity in the region. About $45 \%$ of the studied region presented temporal complementarity above 0.5 in relation to the mean of the three complementarities analyzed in pairs. About $65 \%$ of the region studied had a temporal complementarity index above 0.8 in relation to the complementarity of the three energies together.

The regions with the best complementarity indexes for the implementation of a hybrid system in relation to energy, water and wind were the metropolitan region of Porto Alegre and the Southeast region. In relation to energy, water and photovoltaic solar, the Metropolitan regions of Porto Alegre and Southeast showed the best results. Regarding the wind and solar photovoltaic energies, the Northeast region of the state showed the best result. In relation to the three energies, hydro, wind and photovoltaic solar, the Northeast region was pointed as propitious region for implantation of this system.

The maps obtained are able to help in the study and implantation of wind and 
solar photovoltaic energy in complementation to hydric energy. They can be deployed to meet large and small demands with limited investment resources.

\section{Acknowledgements}

This work was developed as a part of research activities on water resources management and renewable energy at the Instituto de Pesquisas Hidráulicas (IPH), Universidade Federal do Rio Grande do Sul (UFRGS). The authors acknowledge the support received by the institution. The third author acknowledges the financial support received from $\mathrm{CNPq}$ for his research work (proc. $\mathrm{n}$. 309021/2014-6.).

\section{References}

[1] Lilienthal, P.D., Lambert, T.W. and Gilman, P. (2004) Computer Modeling of Renewable Power Systems. In: Cleveland, C.J., Ed., Encyclopedia of Energy, Vol. 1, Elsevier, NREL Report CH-710-36771, Amsterdam, 633-647.

[2] Marinho, M.H.N. and Aquino, R.R.B. (2009) Energy Supply through Seasonal Wind-Hydro Complementarity in the State of Pernambuco. Unpublished Article. http://www.poli.br/index.php?option=com_ph...institucional

[3] National Operator of the Electrical System, ONS (2017) Final Report of DEEP 2023, Decennial Energy Expansion Plan 2023-Ministry of Mines and Energy. www.ons.org.br/home/

[4] https://goo.gl/maps/BxGZpwjdx4R2

[5] Beluco, A., Souza, P.K. and Krenzinger, A. (2003) Energetic Complementarity in Time between Hydro and Solar Energy Resources. Brazilian Journal of Water Resources, 8, 99-109. https://doi.org/10.1016/B978-0-12-409540-3.00007-4

[6] Beluco, A., Souza, P.K. and Krenzinger, A. (2008) A Dimensionless Index Evaluating the Time Complementarity between Solar and Hydraulic Energy. Renewable Energy, 33, 2157-2165. https://doi.org/10.1016/j.renene.2008.01.019

[7] Beluco, A., Souza, P.K. and Krenzinger, A. (2012) A Method to Evaluate the Effect of Complementarity in Time between Hydro and Solar Energy on the Performance of Hybrid Hydro PV Generating Plants. Renewable Energy, 45, 24-30. https://doi.org/10.1016/j.renene.2012.01.096

[8] Beluco, A., Souza, P.K. and Krenzinger, A. (2013) Influence of Different Degrees of Complementarity Solar and Hydro Energy Availability on the Performance of Hybrid Hydro PV Generating Plants. Energy and Power Engineering, 5, 332-342. https://doi.org/10.4236/epe.2013.54034

[9] Bolaños, J.R.M. (2007) Intelligent Supervisory Controller for Small Wind-Dieselbattery Hybrid Systems. Master Dissertation, Energy Engineering, Universidade de São Paulo (USP), 132 p. www.teses.usp.br/teses/...acao_Julio_Martinez.pdf

[10] Hauschild, L. (2006) Evaluation of Operational Strategies of Hybrid PhotovoltaicWind-Diesel Systems. Master Dissertation, Energy, Universidade de São Paulo (USP), $117 \mathrm{p}$.

[11] Pianezzola, G., Krenzinger, A. and Canales, F.A. (2017) Complementary Maps of Wind and Solar Energy Resources for Rio Grande do Sul, Brazil.

[12] Gabriel Fo, L.R.A. (2007) Analysis and Geometric Modeling of the Power Generated by a Hybrid Solar Photovoltaic Wind System. Doctoral Thesis, Energy in Agriculture, Universidade Estadual Paulista, Botucatu, 156 p. (In Portuguese) 
[13] National Water Agency (ANA) Brazil. http://www2.ana.gov.br/Paginas/default.aspx

[14] National Institute of Meteorology (INMET) Brazil. http://www.inmet.gov.br/portal/

[15] Software HOMER, Version 2.68 Beta. The Micropower Optimization Model, Homer Energy. http://www.homerenergy.com

[16] Lambert, T.W., Gilman, P. and Lilienthal, P.D. (2005) Micropower System Modeling with Homer. In: Farret, F.A. and Simões, M.G., Eds., Integration of Alternative Sources of Energy, John Wiley \& Sons, Hoboken, 379-418. https://doi.org/10.1002/0471755621.ch15

[17] Lilienthal, P.D., Lambert, T.W. and Gilman, P. (2004) Computer Modeling of Renewable Power Systems. In: Cleveland, C.J., Ed., Encyclopedia of Energy, Vol. 1, Elsevier, NREL Report CH-710-36771, 633-647.

Submit or recommend next manuscript to SCIRP and we will provide best service for you:

Accepting pre-submission inquiries through Email, Facebook, LinkedIn, Twitter, etc. A wide selection of journals (inclusive of 9 subjects, more than 200 journals)

Providing 24-hour high-quality service

User-friendly online submission system

Fair and swift peer-review system

Efficient typesetting and proofreading procedure

Display of the result of downloads and visits, as well as the number of cited articles

Maximum dissemination of your research work

Submit your manuscript at: http://papersubmission.scirp.org/

Or contact epe@scirp.org 